\title{
Determinants of axial and peripheral bone mass in Chinese adolescents
}

\author{
J C Y Cheng, S S S F Leung, W T K Lee, J T F Lau, N Maffulli, A Y K Cheung, \\ K M Chan
}

\begin{abstract}
Objective-To determine the relation of puberty, physical activity, physical fitness, and calcium intake with bone mineral content (BMC) of the distal radius, and on bone mineral density (BMD) of the L2 to $L 4$ vertebrae in a group of healthy Chinese adolescents.

Design-Cross sectional survey.

Subjects-A group of 179 healthy Chinese adolescents ( 92 boys and 87 girls) aged 12 to 13 years enrolled in the first year of the Tii Junior High School in Shatin, Hong Kong. Ninety four of the pupils enrolled were in the physical education major class $(P E)$, and the other 85 were in the art major class (ARTS).
\end{abstract}

Main outcome measures-Correlation of BMC of the distal radius and BMD of the L2 to $L 4$ vertebrae with level of physical activity, physical fitness (isometric and isokinetic), muscle strength of the upper and lower limb, and calcium intake.

Results-BMC of the distal radius and BMD of the $L 2$ to $L 4$ vertebrae were significantly positively correlated. Univariate and regression analysis showed that age, pubertal staging, physical fitness, and muscle strength were significantly associated with bone mass in a positive way. Calcium intake and type of sport practised did not exert a significant influence on BMC of the distal radius and $B M D$ of the $L 2$ to $L 4$ vertebrae in boys. The results for the BMD of the L2 to $\mathrm{L} 4$ vertebrae were similar in girls and boys; however, in girls, the BMC of the distal radius had a negative correlation with calcium intake. Physical fitness was a significant positive predictor of BMD of the L2 to $L 4$ vertebrae.

Conclusions-Among Chinese adolescents bone mass was positively influenced by certain measures of physical fitness as well as by age, weight, and pubertal stage. (Arch Dis Child 1998;78:524-530)

Keywords: physical activity; muscle strength; bone mass

Ethnicity, physical activity, and calcium intake are known determinants of bone mass in adults. ${ }^{1}$ In a study of children and their parents, up to $60 \%$ of the variance in bone mineral density (BMD) could be ascribed to genetic factors. ${ }^{2}$ This value increased to $80 \%$ in twin studies. ${ }^{3}$ Most studies focused on adults, and there are few quantitative data on the relative contribution of various factors to bone mass acquisition in adolescents during the rapid growth phase. For example, a Dutch group, in a cross sectional study of a heterogeneous population of 500 children, adolescents, and young adults aged from 4 to 20, found that the major independent determinants of BMD were pubertal stage in girls and body weight in boys. ${ }^{4}$

Bone mass of healthy adults is directly correlated with the peak value achieved at skeletal maturity. ${ }^{5}$ In older women, bone mass is also determined by bone loss due to menopause. ${ }^{6}$ In a given individual, peak bone mass is attained in the late $20 \mathrm{~s}$ and early $30 \mathrm{~s}$ : after this age nutritional interventions do not increase bone mass, ${ }^{6}$ although weight bearing exercise may have beneficial effects. ${ }^{7}$ Although bone mass achieved in adulthood is under genetic, ethnic, and hormonal control, ${ }^{89}$ environmental and nutritional factors such as dietary calcium and vitamin $\mathrm{D}$, and physical activity can still contribute significantly to its variability. ${ }^{10-15}$

Most studies of bone mass acquisition in children have been done in white and AfricanAmerican subjects ${ }^{8}$; children of other ethnicity have been considered only as a subgroup, often without their results being analysed in detail. ${ }^{4}{ }^{16}$ Such studies have shown that bone density is lower in whites than in blacks, and still lower in Asians. ${ }^{17}$ Given the scarcity of data available from children of Chinese ancestry, we studied the association of puberty, physical activity, physical fitness, and nutritional factors on axial and peripheral bone mass in a group of healthy Chinese adolescents of a similar age.

\section{Subjects and methods}

Informed consent was obtained from the parents and from each of the 179 healthy adolescents ( 92 boys and 87 girls) enrolled in the first year of the Tii Junior High School in Shatin, Hong Kong. Children underwent physical examination by a fully trained paediatrician to exclude any condition known to affect bone metabolism. No pupil was excluded on this criterion, and none was taking medications known to alter bone or calcium metabolism, or both. The study was approved by the ethical committee for research on human subjects of the medical school of the Chinese University of Hong Kong.

Ninety four of the pupils enrolled were in the physical education major class (PE), and the other 85 were in the art major class (ARTS). Pupils had been assigned to the PE or ARTS classes according to their own and their parents' choice and to school matching procedures, based on the past performance of each pupil in the major subject chosen. 
Table 1 Pubertal stage of children in the physical education and art groups

\begin{tabular}{|c|c|c|c|c|c|c|c|c|c|c|c|}
\hline & \multicolumn{5}{|c|}{ Boys } & & \multicolumn{5}{|c|}{ Girls } \\
\hline & \multicolumn{2}{|c|}{ PE group } & \multicolumn{2}{|c|}{ ARTS group } & \multirow[b]{2}{*}{$p$ value } & & \multicolumn{2}{|c|}{ PE group } & \multicolumn{2}{|c|}{ ARTS group } & \multirow[b]{2}{*}{$p$ value $*$} \\
\hline & $n$ & $\%$ & $n$ & $\%$ & & & $n$ & $\%$ & $n$ & $\%$ & \\
\hline Genitalia & & & & & 0.099 & Breast & & & & & 0.059 \\
\hline Stage 1 & 0 & 0.0 & 3 & 7.7 & & Stage 1 & 0 & 0.0 & 0 & 0.0 & \\
\hline Stage 2 & 23 & 43.4 & 13 & 33.3 & & Stage 2 & 4 & 9.8 & 4 & 8.7 & \\
\hline Stage 3 & 17 & 32.1 & 10 & 25.6 & & Stage 3 & 5 & 12.2 & 16 & 34.8 & \\
\hline Stage 4 & 13 & 24.5 & 11 & 28.2 & & Stage 4 & 10 & 24.4 & 12 & 26.1 & \\
\hline Stage 5 & 0 & 0.0 & 2 & 5.1 & & Stage 5 & 22 & 53.7 & 14 & 30.4 & \\
\hline Pubic hair & & & & & 0.120 & Pubic hair & & & & & 0.118 \\
\hline Stage 1 & 20 & 37.7 & 11 & 28.2 & & Stage 1 & 6 & 14.6 & 4 & 8.7 & \\
\hline Stage 2 & 15 & 28.3 & 14 & 35.9 & & Stage 2 & 3 & 7.3 & 13 & 28.3 & \\
\hline Stage 3 & 10 & 18.9 & 12 & 30.8 & & Stage 3 & 19 & 46.3 & 15 & 32.6 & \\
\hline Stage 4 & 8 & 15.1 & 1 & 2.6 & & Stage 4 & 11 & 26.8 & 13 & 28.3 & \\
\hline Stage 5 & 0 & 0.0 & 1 & 2.6 & & Stage 5 & 2 & 4.9 & 1 & 2.2 & \\
\hline Testicular size & & & & & 0.201 & Menarche & & & & & 0.208 \\
\hline$<4 \mathrm{ml}$ & 1 & 1.9 & 4 & 10.3 & & No & 15 & 36.6 & 23 & 50.0 & \\
\hline $4-12 \mathrm{ml}$ & 29 & 54.7 & 21 & 53.8 & & Yes & 26 & 63.4 & 23 & 50.0 & \\
\hline$>12 \mathrm{ml}$ & 23 & 43.4 & 14 & 35.9 & & & & & & & \\
\hline
\end{tabular}

LEVEL OF SPORTS PARTICIPATION

Each pupil was interviewed by one of the investigators to determine the type (ball games, water sports, track and field, and other) and the level (national/school team or recreational) of sport practised. In the PE group, $71.7 \%$ of the boys belonged to the national/school team, whereas none of the boys in the ARTS group $\operatorname{did}(\mathrm{p}<0.001)$.

DIETARY NUTRITION AND CALCIUM INTAKE

Each pupil was interviewed separately by a fully trained dietitian. A quantitative food frequency questionnaire, ${ }^{18}$ modified and validated for the Hong Kong Chinese population, ${ }^{914}$ was used to assess individual dietary intake during the previous two months. Nutrient intake of the various food items was calculated from a comprehensive computerised food database compiled from previously published sources. ${ }^{19-22}$

\section{ANTHROPOMETRIC MEASUREMENTS AND}

PUBERTAL STAGING

All anthropometric measurements were performed by one of two fully trained paediatricians, whose intratester and intertester variability was such that the results for each measurement were reproduced within $5 \%$ of the initial value in at least $80 \%$ of cases. Height without shoes was measured to the nearest $0.1 \mathrm{~cm}$ using a portable Harpenden Stadiometer (Holtain, Crosswell, UK). ${ }^{23}$ Weight in light vest and knickers was measured to the nearest $0.1 \mathrm{~kg}$ using a Seca digital physician's scale (Seca Ltd, Bonn, Germany). ${ }^{24}{ }^{25}$ Pubertal staging was done according to Tanner's criteria. ${ }^{26}$ Menarcheal status was assessed by individual interview. Limb dominance was determined by asking the children which hand they wrote with and which leg they kicked a ball with.

BONE MASS MEASUREMENTS

The bone mineral content (BMC) and the width of both distal radii was measured using the Norland 2780 single beam photon absorptiometer (Norland Corporation, Fort Atkinson, Wisconsin, USA) (SPA). The BMD of the L2 to L4 lumbar vertebrae was measured using the Norland Dual-energy $x$ ray absorptiometer (DEXA), Model XR-26 (Norland Corporation). These measurements were taken and the machines calibrated daily in accordance with the manufacturer's instructions by one of two trained technicians.

Table 2 Comparison of bone mineral status and physical fitness between physicial education and art groups

\begin{tabular}{|c|c|c|c|c|c|c|c|c|c|c|c|c|c|c|}
\hline & \multicolumn{7}{|c|}{ Boys } & \multicolumn{7}{|c|}{ Girls } \\
\hline & \multicolumn{3}{|c|}{ PE group } & \multicolumn{3}{|c|}{ ARTS group } & \multirow[b]{2}{*}{$p$ value ${ }^{\star}$} & \multicolumn{3}{|c|}{ PE group } & \multicolumn{3}{|c|}{ ARTS group } & \multirow[b]{2}{*}{$p$ value ${ }^{\star}$} \\
\hline & $n$ & Mean & $S E$ & $n$ & Mean & $S E$ & & $n$ & Mean & $S E$ & $n$ & Mean & $S E$ & \\
\hline Calcium intake (mg/day) & 53 & 736.1 & 36.74 & 39 & 702.7 & 38.9 & 0.542 & 41 & 563.9 & 31.9 & 46 & 556.7 & 34.6 & 0.880 \\
\hline Bone width of radius $(\mathrm{cm})$ & 53 & 1.07 & 0.015 & 39 & 1.02 & 0.020 & 0.061 & 41 & 1.06 & 0.015 & 46 & 1.001 & 0.014 & 0.002 \\
\hline $\mathrm{BMC}$ radius $(\mathrm{g} / \mathrm{cm})$ & 53 & 0.63 & 0.015 & 39 & 0.57 & 0.015 & 0.009 & 41 & 0.67 & 0.013 & 46 & 0.63 & 0.013 & 0.055 \\
\hline $\mathrm{BMD} \mathrm{L} 2-\mathrm{L} 4\left(\mathrm{~g} / \mathrm{cm}^{2}\right)$ & 53 & 0.66 & 0.019 & 39 & 0.58 & 0.012 & 0.003 & 41 & 0.79 & 0.018 & 46 & 0.72 & 0.015 & 0.002 \\
\hline \multicolumn{15}{|l|}{ Physical fitness tests } \\
\hline 3 minute step test (total beats) & 53 & 126.8 & 2.7 & 39 & 137.4 & 3.32 & 0.014 & 41 & 136.1 & 3.8 & 46 & 147.2 & 3.43 & 0.032 \\
\hline Sit and reach test $(\mathrm{cm})$ & 53 & 30.1 & 0.87 & 39 & 28.4 & 0.8 & 0.175 & 41 & 35.8 & 0.92 & 46 & 32.8 & 1.06 & 0.039 \\
\hline $1 \mathrm{~min}$ sit up test (times) & 53 & 33.0 & 1.01 & 39 & 25.8 & 1.8 & 0.001 & 41 & 27.3 & 1.38 & 46 & 20.9 & 1.13 & $<0.001$ \\
\hline Vertical jump (cm) & 53 & 44.3 & 1.03 & 39 & 38.7 & 1.36 & 0.001 & 41 & 37.7 & 0.98 & 46 & 33.1 & 0.89 & 0.001 \\
\hline Grip strength (kg) & 53 & 22.1 & 0.86 & 39 & 20.1 & 0.84 & 0.103 & 41 & 21.1 & 0.55 & 46 & 19.7 & 0.61 & 0.113 \\
\hline \multicolumn{15}{|l|}{ Isokinetic peak extension } \\
\hline \multirow{2}{*}{\multicolumn{15}{|c|}{ Isokinetic peak flexion torque }} \\
\hline & & & & & & & & & & & & & & \\
\hline$(\mathrm{Nm})$ & 37 & 136.9 & 4.1 & 27 & 131.0 & 5 & 0.368 & 34 & 104.7 & 3.2 & 37 & 89.8 & 2.4 & $<0.001$ \\
\hline
\end{tabular}

${ }^{\star}$ Independent $t$ test. 
Table 3 Correlation analysis of variables associated with bone mass

\begin{tabular}{|c|c|c|c|c|c|c|c|c|c|c|c|c|}
\hline & \multicolumn{6}{|c|}{$B M C$ of the distal radius } & \multicolumn{6}{|c|}{$B M D$ of the $L 2$ to $L 4$ vertebrae } \\
\hline & \multicolumn{3}{|c|}{ Boys } & \multicolumn{3}{|c|}{ Girls } & \multicolumn{3}{|c|}{ Boys } & \multicolumn{3}{|c|}{ Girls } \\
\hline & $n$ & $r$ & $p$ value ${ }^{\star}$ & $n$ & $r$ & $p$ value ${ }^{\star}$ & $n$ & $r$ & $p$ value ${ }^{\star}$ & $n$ & $r$ & $p$ value ${ }^{\star}$ \\
\hline Age & 92 & 0.542 & $<0.001$ & 87 & 0.275 & 0.010 & 92 & 0.685 & $<0.001$ & 87 & 0.313 & 0.003 \\
\hline Weight & 92 & 0.671 & $<0.001$ & 87 & 0.534 & $<0.001$ & 92 & 0.591 & $<0.001$ & 87 & 0.647 & $<0.001$ \\
\hline Height & 92 & 0.652 & $<0.001$ & 87 & 0.479 & $<0.001$ & 92 & 0.647 & $<0.001$ & 87 & 0.462 & $<0.001$ \\
\hline Bone width & 92 & 0.764 & $<0.001$ & 87 & 0.714 & $<0.001$ & 92 & 0.558 & $<0.001$ & 87 & 0.340 & 0.001 \\
\hline Length of L2-L4 & 92 & 0.657 & $<0.001$ & 87 & 0.471 & $<0.001$ & 92 & 0.702 & $<0.001$ & 87 & 0.618 & $<0.001$ \\
\hline Calcium intake & 92 & 0.105 & 0.320 & 87 & -0.264 & 0.014 & 92 & 0.099 & 0.349 & 87 & -0.142 & 0.189 \\
\hline \multicolumn{13}{|l|}{ Physical fitness } \\
\hline 3 minute step test recovery index & 92 & 0.059 & 0.580 & 87 & 0.007 & 0.946 & 92 & 0.064 & 0.547 & 87 & 0.098 & 0.368 \\
\hline Sit and reach test & 92 & 0.526 & $<0.001$ & 87 & 0.250 & 0.020 & 92 & 0.340 & 0.001 & 87 & 0.336 & 0.001 \\
\hline 1 minute sit ups & 92 & 0.200 & 0.056 & 85 & 0.309 & 0.004 & 92 & 0.219 & 0.036 & 85 & 0.341 & 0.001 \\
\hline Grip strength & 92 & 0.777 & $<0.001$ & 87 & 0.539 & $<0.001$ & 92 & 0.763 & $<0.001$ & 87 & 0.555 & $<0.001$ \\
\hline Vertical jump & 92 & 0.368 & $<0.001$ & 87 & 0.149 & 0.168 & 92 & 0.506 & $<0.001$ & 87 & 0.280 & 0.009 \\
\hline
\end{tabular}

$\star$ Pearson's correlation.

The reproducibility in evaluating the radius in two successive scans without repositioning of the subjects were $2.09 \%$ and $2.06 \%$ respectively for $\mathrm{BMC}$ of the distal radius and bone width. Reproducibility of the DEXA scan results was within $1.4 \%$ for the L2 to L4 lumbar vertebrae.

PHYSICAL FITNESS ASSESSMENT

The following tests were performed in the order reported hereinafter according to the instructions of the American College of Sports Medicine (1995), the American Alliance for Health Physical Education, Recreation and Dance, ${ }^{27}$ or the manufacturers of the testing apparatus as appropriate. All tests were done after the children had performed stretching exercises for five minutes and cycled for a further five minutes on a commercially available cycle ergometer (Monark model 818E, Mon- ark AB, Stockholm, Sweden) at a load setting of zero. The dominant limb was tested first, and the non-dominant limb was tested after a three minute rest (handgrip test) or a five minute (isokinetic test) rest. A three minute rest was allowed between each test. Children were verbally encouraged to produce maximal effort. The tests included (1) recovery index after a three minute step test ${ }^{28}$; (2) sit and reach test, ${ }^{29}$ using the Sit-and-Reach 5111 testing kit (Takei \& Co Ltd, Tokyo, Japan); (3) one minute sit up test; (4) bilateral handgrip, ${ }^{27}$ using the Grip D 5101 dynamometer (Takei \& Co Ltd, Tokyo, Japan); (5) vertical jump ${ }^{29}$; and (6) bilateral isokinetic quadriceps and hamstring peak flexion and extension torque test at $60 \%$ second and $180 \%$ second. ${ }^{30}$ A Cybex $\mathrm{II}^{+}$ dynamometer (Cybex, Lumex Inc Ronkonkoma, New York, USA) equipped with

Table 4 Univariate analysis of independent variables with BMC of the distal radius

\begin{tabular}{|c|c|c|c|c|c|c|c|c|}
\hline & \multicolumn{4}{|c|}{ Boys } & \multicolumn{4}{|c|}{ Girls } \\
\hline & $n$ & Mean & $S E$ & p value & $n$ & Mean & $S E$ & p value \\
\hline \multicolumn{9}{|l|}{ Genitalia } \\
\hline Stage $1,2,3$ & 66 & 0.585 & 0.011 & \multirow[t]{2}{*}{$0.002^{\star}$} & & & & \\
\hline Stage 4,5 & 26 & 0.661 & 0.024 & & & & & \\
\hline \multicolumn{9}{|l|}{ Testicular size } \\
\hline$\leqslant 12 \mathrm{ml}$ & 55 & 0.575 & 0.013 & \multirow[t]{2}{*}{$<0.001^{\star}$} & & & & \\
\hline$>12 \mathrm{ml}$ & 37 & 0.653 & 0.017 & & & & & \\
\hline \multicolumn{9}{|l|}{ Pubic hair } \\
\hline Stage $1,2,3$ & 82 & 0.591 & 0.010 & \multirow[t]{2}{*}{$<0.001^{\star}$} & 60 & 0.619 & 0.011 & \multirow[t]{2}{*}{$<0.001^{\star}$} \\
\hline Stage 4,5 & 10 & 0.735 & 0.039 & & 27 & 0.694 & 0.011 & \\
\hline \multicolumn{9}{|l|}{ Breast } \\
\hline Stage $1,2,3$ & & & & & 29 & 0.585 & 0.016 & \multirow{2}{*}{$<0.001^{\star}$} \\
\hline Stage 4,5 & & & & & 58 & 0.671 & 0.010 & \\
\hline \multicolumn{9}{|l|}{ Menarche } \\
\hline No & & & & & 38 & 0.603 & 0.015 & \multirow[t]{2}{*}{$<0.001^{\star}$} \\
\hline Yes & & & & & 49 & 0.673 & 0.010 & \\
\hline \multicolumn{9}{|l|}{ Group } \\
\hline Art & 39 & 0.573 & 0.015 & \multirow[t]{2}{*}{$0.009^{\star}$} & 46 & 0.626 & 0.013 & \multirow[t]{2}{*}{$0.055^{\star}$} \\
\hline Physical education & 53 & 0.631 & 0.015 & & 41 & 0.661 & 0.013 & \\
\hline \multicolumn{9}{|l|}{ Ball games } \\
\hline No & 62 & 0.602 & 0.014 & \multirow[t]{2}{*}{$0.512^{\star}$} & 69 & 0.633 & 0.011 & \multirow[t]{2}{*}{$0.056^{\star}$} \\
\hline Yes & 30 & 0.617 & 0.017 & & 18 & 0.677 & 0.018 & \\
\hline \multicolumn{9}{|l|}{ Track and field } \\
\hline No & 74 & 0.594 & 0.011 & \multirow[t]{2}{*}{$0.078^{\star}$} & 75 & 0.642 & 0.010 & \multirow[t]{2}{*}{$0.792^{\star}$} \\
\hline Yes & 18 & 0.657 & 0.032 & & 12 & 0.649 & 0.018 & \\
\hline \multicolumn{9}{|l|}{ Water sports } \\
\hline No & 83 & 0.603 & 0.012 & \multirow[t]{2}{*}{$0.355^{\star}$} & 80 & 0.642 & 0.009 & \multirow[t]{2}{*}{$0.781^{\star}$} \\
\hline Yes & 9 & 0.638 & 0.023 & & 7 & 0.651 & 0.045 & \\
\hline \multicolumn{9}{|l|}{ Other sports } \\
\hline No & 88 & 0.605 & 0.011 & \multirow[t]{2}{*}{$0.677^{\star}$} & 79 & 0.641 & 0.010 & $0.578^{\star}$ \\
\hline Yes & 4 & 0.651 & 0.100 & & 8 & 0.659 & 0.040 & \\
\hline Level of sports & & & & & & & & \\
\hline PE group-National/school team & 38 & 0.635 & 0.017 & $0.040 \dagger$ & 30 & 0.672 & 0.015 & $0.066 \dagger$ \\
\hline PE group-Recreational purpose & 15 & 0.622 & 0.032 & & 11 & 0.634 & 0.023 & \\
\hline ARTS group-Recreational purpose & 33 & 0.572 & 0.016 & & 39 & 0.623 & 0.014 & \\
\hline
\end{tabular}

^Independent $t$ test; †analysis of variance. 
Table 5 Univariate analysis of independent variables with BMD of the L2 to L4 vertebrae

\begin{tabular}{|c|c|c|c|c|c|c|c|c|}
\hline & \multicolumn{4}{|c|}{ Boys } & \multicolumn{4}{|c|}{ Girls } \\
\hline & $n$ & Mean & $S E$ & $p$ value & $n$ & Mean & $S E$ & p value \\
\hline \multicolumn{9}{|l|}{ Genitalia } \\
\hline Stage $1,2,3$ & 66 & 0.592 & 0.008 & \multirow[t]{2}{*}{$0.001^{\star}$} & & & & \\
\hline Stage 4,5 & 26 & 0.718 & 0.034 & & & & & \\
\hline \multicolumn{9}{|l|}{ Testicular size } \\
\hline$\leqslant 12 \mathrm{ml}$ & 55 & 0.582 & 0.009 & \multirow{2}{*}{$<0.001^{\star}$} & & & & \\
\hline$>12 \mathrm{ml}$ & 37 & 0.696 & 0.025 & & & & & \\
\hline \multicolumn{9}{|l|}{ Pubic hair } \\
\hline Stage $1,2,3$ & 82 & 0.605 & 0.009 & \multirow[t]{2}{*}{$0.015^{\star}$} & 60 & 0.716 & 0.013 & \multirow[t]{2}{*}{$<0.001^{\star}$} \\
\hline Stage 4,5 & 10 & 0.815 & 0.070 & & 27 & 0.840 & 0.017 & \\
\hline \multicolumn{9}{|l|}{ Breast } \\
\hline Stage $1,2,3$ & & & & & 29 & 0.656 & 0.016 & \multirow[t]{2}{*}{$<0.001^{\star}$} \\
\hline Stage 4,5 & & & & & 58 & 0.804 & 0.011 & \\
\hline \multicolumn{9}{|l|}{ Menarche } \\
\hline No & & & & & 38 & 0.679 & 0.015 & \multirow{2}{*}{$<0.001^{\star}$} \\
\hline Yes & & & & & 49 & 0.813 & 0.013 & \\
\hline \multicolumn{9}{|l|}{ Group } \\
\hline Art & 39 & 0.587 & 0.012 & \multirow[t]{2}{*}{$0.003^{\star}$} & 46 & 0.721 & 0.015 & \multirow[t]{2}{*}{$0.002^{\star}$} \\
\hline Physical education & 53 & 0.658 & 0.019 & & 41 & 0.792 & 0.018 & \\
\hline \multicolumn{9}{|l|}{ Ball games } \\
\hline No & 62 & 0.615 & 0.016 & \multirow[t]{2}{*}{$0.147^{\star}$} & 69 & 0.742 & 0.013 & \multirow[t]{2}{*}{$0.040^{\star}$} \\
\hline Yes & 30 & 0.654 & 0.019 & & 18 & 0.803 & 0.024 & \\
\hline \multicolumn{9}{|l|}{ Track and field } \\
\hline No & 74 & 0.608 & 0.009 & \multirow[t]{2}{*}{$0.054^{\star}$} & 75 & 0.749 & 0.013 & \multirow[t]{2}{*}{$0.277^{\star}$} \\
\hline Yes & 18 & 0.711 & 0.049 & & 12 & 0.787 & 0.034 & \\
\hline \multicolumn{9}{|l|}{ Water sports } \\
\hline No & 83 & 0.631 & 0.014 & \multirow[t]{2}{*}{$0.251^{\star}$} & 80 & 0.752 & 0.013 & \multirow[t]{2}{*}{$0.414^{\star}$} \\
\hline Yes & 9 & 0.602 & 0.020 & & 7 & 0.788 & 0.036 & \\
\hline \multicolumn{9}{|l|}{ Other sports } \\
\hline No & 88 & 0.629 & 0.013 & \multirow[t]{2}{*}{$0.702^{\star}$} & 79 & 0.752 & 0.012 & $0.529^{\star}$ \\
\hline Yes & 4 & 0.605 & 0.048 & & 8 & 0.778 & 0.054 & \\
\hline Level of sports & & & & & & & & \\
\hline PE group-National/school team & 38 & 0.662 & 0.017 & $0.023 \dagger$ & 30 & 0.801 & 0.020 & $0.005 \dagger$ \\
\hline PE group-Recreational purpose & 15 & 0.647 & 0.055 & & 11 & 0.769 & 0.038 & \\
\hline ARTS group-Recreational purpose & 33 & 0.583 & 0.014 & & 39 & 0.714 & 0.016 & \\
\hline
\end{tabular}

${ }^{\star}$ Independent $t$ test; †analysis of variance.

a HUMAC computer system (Computer Sports Medicine Inc, Totowa, New Jersey, USA) was used. The variables measured were peak torque $(\mathrm{Nm})$, average work (joules), and average power (watts). Each test consisted of a trial phase of four submaximal and two maximal contractions at the given testing speed, a one minute rest, and an actual test phase of three continuous maximal contractions. Knee extension was tested first at $60 \%$ second, and then at $180 \%$ second, with a two minute rest between the two speeds. After a further two minute rest, knee flexion was tested starting at $60 \%$ second and progressed to $180 \%$ second after a two minute rest. The nondominant limb was tested in the same way after a five minute rest.

For tests 2, 4, 5, and 6, three attempts were allowed, and the best result used for analysis.
PHYSICAL ACTIVITY ASSESSMENT

To assess physical activity over the past six months, each pupil was individually interviewed and information gathered through self report on: (a) type of major regular sportsball games, track and field athletics, water sports, others; or (b) level of sports participation-PE group: national/school team members; PE group: recreational purpose; ARTS group.

STATISTICAL ANALYSIS

Descriptive statistics were calculated. The relations were studied between anthropometric measurements, pubertal staging, physical fitness, level of physical activities, and BMC of the distal radius and $\mathrm{BMD}$ of the $\mathrm{L} 2$ to $\mathrm{L} 4$ vertebrae. Univariate analyses by Student's $t$ test, $\chi^{2}$ test, and Pearson's correlation coefficients

Table 6 Summary of stepwise regression model for the prediction of BMC of the distal radius and of the BMD of the L2 to $L 4$ vertebrae

\begin{tabular}{|c|c|c|c|c|c|c|c|c|}
\hline \multirow{3}{*}{$\begin{array}{l}\text { Independent } \\
\text { variables }\end{array}$} & \multicolumn{4}{|c|}{$B M C$ of the distal radius } & \multicolumn{4}{|c|}{$B M D$ of the $L 2$ to $L 4$ vertebrae } \\
\hline & \multicolumn{2}{|l|}{ Boys } & \multicolumn{2}{|l|}{ Girls } & \multicolumn{2}{|l|}{ Boys } & \multicolumn{2}{|l|}{ Girls } \\
\hline & Coefficients $b$ & $p$ value & Coefficients $b$ & $p$ value & Coefficients $b$ & $p$ value & Coefficients $b$ & $p$ value \\
\hline Age & 0.056 & $<0.0001$ & 0.033 & 0.0096 & 0.090 & $<0.0001$ & 0.045 & 0.0069 \\
\hline Weight & 0.004 & 0.0002 & 0.003 & 0.0088 & 0.007 & $<0.0001$ & 0.009 & $<0.0001$ \\
\hline Bone width & 0.332 & $<0.0001$ & 0.516 & $<0.0001$ & & & & \\
\hline Flex test & 0.003 & 0.0028 & & & & & & \\
\hline Pubic hair & & & 0.046 & 0.0012 & & & 0.060 & 0.0013 \\
\hline Jump & & & & & 0.004 & $<0.0001$ & & \\
\hline Sit up test & & & & & & & 0.005 & $<0.0001$ \\
\hline Constant & -0.699 & & -0.425 & & -0.948 & & -0.321 & \\
\hline $\mathrm{R}^{2}$ & 0.779 & & 0.673 & & 0.740 & & 0.670 & \\
\hline
\end{tabular}

The variables entered in the analysis were: age, weight, height, bone width, genitalia/breast development, pubic hair, testicular size/ menarche, group, level of sports, recovery index after the 3 minute step test, sit and reach test, 1 minute sit up test, grip strength, vertical jump, and calcium intake. 
were used to identify significant variables, which were then used for stepwise multiple regression analysis. The analyses were done separately for each sex to allow for the different measures of pubertal stages. Factors commonly predictive of BMC and BMD (for example, age, weight, height, and bone width) were given higher priorities to enter the regression model. Our goal was to identify other possible predicting factors. $p$ values less than 0.05 were considered significant. SPSS for Windows version 6.0 was used for the statistical analyses. ${ }^{31}$

\section{Results}

ANTHROPOMETRY AND PUBERTY STAGING

Age, body weight, and height were not significantly different between the two groups. Of the boys in the PE group, $25 \%$ had their genitalia at Tanner stage $4,15 \%$ had pubic hair at stage 4 , and $43 \%$ had a testicular size greater than $12 \mathrm{ml}$ (table 1). Among the girls in the PE group, $78 \%$ showed a stage of breast development of 4 or 5 . Pubic hair had reached stage 4 or 5 in $32 \%$ of the girls in the PE group, and $63 \%$ of them were post-menarcheal. Children in the ARTS group showed similar findings $(\mathrm{p}>0.05)$.

BONE MASS, CALCIUM INTAKE, PHYSICAL ACTIVITIES, PHYSICAL FITNESS, AND STRENGTH There were no significant differences between the BMC of the dominant and non-dominant radii, and between dominant and nondominant limb in handgrip and isokinetic testing (paired sample $t$ test). For subsequent analysis the dominant limb values were used.

Among the boys in the PE group, the mean (SE) BMC of the distal radius $(0.631$ $(0.015) \mathrm{g} / \mathrm{cm})$ was greater compared with boys in the ARTS group $(0.573(0.015) \mathrm{g} / \mathrm{cm})$ $(\mathrm{p}=0.009)$. Boys in the PE group also had a greater BMD of the L2 to L4 vertebrae $(0.658$ $\left.(0.019) \mathrm{g} / \mathrm{cm}^{2}\right) \quad v \quad 0.587 \quad\left(0.012 \mathrm{~g} / \mathrm{cm}^{2}\right)$ $(\mathrm{p}=0.003)$. Calcium intake and bone width of the distal radius were not significantly different among the two groups (table 2).

Among the girls, there were significant differences between the PE and ARTS groups in all variables examined except calcium intake, BMC of the distal radius, and grip strength. Girls in the PE group had a greater mean (SE) BMD of their L2 to L4 vertebrae $\left(0.792(0.018) \mathrm{g} / \mathrm{cm}^{2}\right)$ compared with those in the ARTS group $\left(0.721 \quad(0.015) \mathrm{g} / \mathrm{cm}^{2}\right)$ $(p=0.002)$. The bone width of their distal radius was also larger $(1.065(0.015) \mathrm{cm} v$ $1.001(0.014) \mathrm{cm})(\mathrm{p}=0.002)($ table 2$)$.

The mean (SE) BMC of the distal radius among boys $\left(0.607(0.011) \mathrm{g} / \mathrm{cm}^{2}\right)$ was smaller compared with girls $\left(0.643(0.009) \mathrm{g} / \mathrm{cm}^{2}\right)$ $(\mathrm{p}=0.014)$. Boys also had a smaller BMD of the L2 to L4 vertebrae $\left(0.628(0.013) \mathrm{g} / \mathrm{cm}^{2}\right)$ compared with girls $\left(0.754 \quad(0.012) \mathrm{g} / \mathrm{cm}^{2}\right)$ $(p<0.001)$. This probably reflects the larger proportion of girls who were at a more advanced pubertal stage.
BONE MASS: UNIVARIATE ANALYSIS

Tables 3, 4, and 5 summarise the results of the univariate analysis of the relation between independent variables (calcium intake, anthropometric measurements, pubertal stage, bone width, physical fitness, physical activity) and $\mathrm{BMC}$ of the distal radius and BMD of the L2 to $\mathrm{L} 4$ vertebrae.

In boys, age, anthropometric variables, physical fitness variables, and pubertal staging were positively associated with the BMC of the distal radius and $\mathrm{BMD}$ of the $\mathrm{L} 2$ to $\mathrm{L} 4$ vertebrae. The length of L2 to L4, bone width of forearm, whether the pupils were in the PE or in the ARTS group, and most of all physical fitness tests were positively associated with $\mathrm{BMC}$ of the distal radius and BMD of the L2 to $\mathrm{L} 4$ vertebrae. Calcium intake and type of sport were not associated with BMC of the distal radius and with $\mathrm{BMD}$ of the $\mathrm{L} 2$ to $\mathrm{L} 4$ vertebrae.

The situation was similar for girls. However, $\mathrm{BMC}$ of the distal radius showed a negative correlation with calcium intake. Whether the girls were in the PE or ARTS groups just failed to show a significant effect on BMC of the distal radius. Calcium intake did not show a significant association with BMD of the L2 to L4 vertebrae, but it was significantly associated with the type of major subject class (PE or ARTS $)$ in the girls $(p=0.002)$.

BONE MASS: STEPWISE REGRESSION ANALYSIS The analysis identified the variables predictive of $\mathrm{BMC}$ of the distal radius and of BMD of the L2 to L4 vertebrae. Age, weight, height, and bone width were given high priority to enter the stepwise model, as they have been identified as significant predictors of BMC of the distal radius and $\mathrm{BMD}$ of the $\mathrm{L} 2$ to $\mathrm{L} 4$ vertebrae. ${ }^{89}$ The other variables listed in the previous sections - that is, pubertal stage, group, level of sport, type of sport, physical fitness, and calcium intake - were all given equal chance to enter the model. Stepwise regression analysis showed that many of the factors, including inclusion in the PE or in the ARTS group, became non-significant. Table 6 summarises the remaining significant predictive factors.

Among boys and girls the common positive predictors of BMC of the distal radius were age, body weight, and bone width of the distal radius. Flexibility in boys and pubic hair stage in girls were found to be additional significant factors.

Findings were similar for BMD of the $\mathrm{L} 2$ to L4 vertebrae. Age and body weight remained significant positive predictors. Vertical jump score and sit up test score, pubic hair stage in boys and girls, respectively were positively correlated with BMD of the L2 to L4 vertebrae. Bone width of the distal forearm did not predict BMD of the L2 to L4 vertebrae.

\section{Discussion}

Peak bone mass is attained in early adulthood and, after a period when it remains relatively constant, a slow progressive decline is observed. ${ }^{6}$ Actual bone mass and rate of decline are affected by multiple factors, the 
most important of which are genetic make up, age, sex, calcium intake, physical exercise, and other environmental lifestyle factors. Genetic influence could account for $70-80 \%$ of peak bone mass. ${ }^{89}$ Timing of the attainment of peak bone mass varies among different ethnic groups. For example, black people achieve a significantly higher bone mass and at an earlier age than white people do. ${ }^{8}$

Intervention studies have shown that in adult and older women ${ }^{11}$ and children ${ }^{13}$ sufficient calcium supplements can significantly increase bone mass even in children with calcium intake within recommended limits. ${ }^{13-15}$ Most researchers have found that programmed physical exercise and training, quantity of exercise, endurance exercise, and weight bearing exercise exert a significant positive effect on bone mass acquisition. ${ }^{7} 101214$

Studies in children have shown the increase of bone mass with age, the correlation with calcium intake, body weight and height, and a significant difference between boys and girls and between different ethnic groups. However, detailed studies on the effects of physical exercise and of puberty on bone mass acquisition are relatively few, ${ }^{32-34}$ and their results are controversial. For example, a recent study from Canada showed that weight training in adolescent girls does not exert any significant influence on the increase of total body and lumbar spine BMD.

This study focused on adolescents and the various factors potentially affecting bone mass. These included pubertal stages, type and quantity of physical activity, physical fitness and strength, and calcium intake. Univariate analysis showed a significant positive correlation between BMC of the distal radius and BMD of the L2 to L4 vertebrae and age, weight, height, pubertal stage, bone width of distal radius, type of sport and physical fitness, and strength in both sexes. The effect of the different level of sports and frequency of sports participation were found to affect BMD of the lumbar spine more significantly than BMC of the distal radius. This is in keeping with other studies that have shown that BMD of the spine reflects more accurately the effect of physical exercise than BMC of the distal radius. ${ }^{35}$ The correlation with calcium intake was not significant, and the type of sport played affected neither BMC of the distal radius nor BMD of the L2 to L4 vertebrae.

When subjected to multiple regression analysis, it was confirmed that age, weight, and bone width are significant predictors of BMC of the distal radius and of $\mathrm{BMD}$ of the $\mathrm{L} 2$ to $\mathrm{L} 4$ vertebrae, at least in the study design adopted in our sample. Furthermore, BMC of the distal radius and $\mathrm{BMD}$ of the $\mathrm{L} 2$ to $\mathrm{L} 4$ vertebrae are also associated with some fitness variables in both sexes, and with pubertal stages. Pupils with higher pubertal stages therefore would be expected to have higher BMC of the distal radius or higher BMD of the lumbar spine.

In conclusion, BMC of the distal radius and $\mathrm{BMD}$ of the L2 to L4 vertebrae in boys were correlated with age, anthropometric variables, physical fitness, and pubertal stage. Calcium intake and type of sport practised did not exert a significant influence. In girls, while the results for BMD of the L2 to L4 vertebrae were similar to that found in boys, BMC of the distal radius showed a negative correlation with calcium intake. As in other ethnic groups, age and body weight were significant predictors of $\mathrm{BMC}$ of the distal radius. Physical fitness was a significant predictor of BMD of the L2 to L4 vertebrae, confirming the findings of other investigators that exercise has a significant effect on the lumbar spine.

This study was financed by a mainline research grant of the Hong Kong Research Council. Many thanks are given to $\mathrm{Mr}$ Andy Sher, chief medical technician, for the help given in performing the $\mathrm{BMC}$ and $\mathrm{BMD}$ measurements. The advice and criticism given by Dr Nicola Thompson in preparing the manuscript are gratefully acknowledged. We are grateful to Miss script are gratefully acknowledged. We are grateful to Miss
Linda Lothian for the help given in preparing the manuscript.

1 Maffulli N, King JB. Effects of physical activity on some components of the skeletal system. Sports Med 1992;13:393-407.

2 Krall EA, Dawson-Hughes B. Inheritable and lifestyle determinants of bone mineral density. F Bone Miner Res 1993;8:1-9.

3 Dequeker J, Nijs J, Verstraeten A, Gensens P, Gevers G. Genetic determinants of bone mineral content at the spine and radius: a twin study. Bone 1987;8:207-9.

4 Boot AM, De Ridder MAJ, Pols HAP, et al. Bone mineral density in children and adolescents: relation to puberty, calcium intake, and physical activity. $\mathcal{F}$ Clin Endocrinol Metab 1997;82:57-62.

5 Riggs BL, Wahner HW, Dunn WL, Mazess RB, Offord KP, Melton LJ III. Differential changes in bone mineral density of the appendicular and axial skleleton with aging. 7 Clin Invest $1981 ; 67: 328-35$.

6 Vico L, Prallet B, Chappard D, Pallot-Prades B, Pupier R, Alexandre C. Contributions of chronological age, age at menarche and menopause and of anthropometric parameters to axial and peripheral bone densities. Osteoporosis Int 1992;2:153-8.

7 Snow-Harter C, Bouxsein ML, Lewis BT, Carter DR, Marcus R. Effects of resistance and endurance exercise on bone mineral status of young women: a randomized exercise intervention trial. $\mathcal{F}$ Bone Miner Res 1992; 7:761-9.

8 Gilsanz V, Roe TF, Mora S, Costin G, Goodman G. Changes in vertebral bone density in black girls and white girls during childhood and puberty. $N$ Engl $\mathscr{f} M e d$ 1991;325:1597-1600.

9 Cheng JCY, Mahmood A, Hui PW. Bone mineral content in Chinese children. F Hong Kong Med Assoc 1993;45:209-14.

10 Grimston SK, Willows ND, Hanley DA. Mechanical loading regime and its relationship to bone mineral density in children. Med Sci Sports Exerc 1993;25:203-10.

11 Anderson JJ, Metz JA. Contributions of dietary calcium and physical activity to primary prevention of osteoporosis in
females. F Am Coll Nutr 1993;12:378-83.

12 Menkes A, Mazel S, Redmond RA, et al. Strength training increases regional bone mineral density and bone remodeling in middle-aged and older men. $f$ Appl Physiol 1993;74:2478-84

13 Lloyd T, Andon MB, Rollings N, et al. Calcium supplementation and bone mineral density in adolescent girls. $f A M A$ 1993;270:841-4

14 Lau EM, Woo J, Leung PC, Swaminathan R, Leung D. The effects of calcium supplementation and exercise on bone density in elderly Chinese women. Osteoporosis Int 1992;2: 168-73.

15 Lee WTK, Leung SSF, Wang SH, et al. Double-blind, controlled calcium supplementation and bone mineral accretion in children accustomed to a low-calcium diet. $A m \mathcal{F}$ Clin Nutr 1994;60:744-50.

16 Nelson DA, Simpson PM, Johnson CC, Barondess DA, Kleerekoper M. Accumulation of whole body skeletal mass in third- and fourth-grade children: effects of age, gender, in third- and fourth-grade children: effects of age, gender

17 Luckey MM, Meier DE, Mandeli JP, DaCosta MC, Hubbard ML, Goldsmith SJ. Radial and vertebral bone density in white and black women: evidence for racial differences in premenopausal bone homeostasis. $f$ Clin Endocrinol Metab 1989;69:762-70.

18 Lee WTK, Leung SSF, Lui SSH, et al. Relationship between long term calcium intake and bone mineral content of children aged from birth to 5 years. Br F Nutr 1993;70:235-48.

19 Institute of Nutrition and Food Hygiene. Food composition table. Beijing: Chinese People's Health Publishing Company, 1991.

20 Paul AA, Southgate DAT, McCance JH. Widdowson's the composition of foods. 4th ed. London: HMSO, 1978.

21 US Department of Health, Education and Welfare. Food composition. Table for use in south east Asia. Bethesda, composition. Table for use in south east Asia. Bethesda, fare, 1972 . 
22 Steele MF, Mattox JW. Correlation of arm-span and height in young women of two races. Ann Hum Biol 1987;14:445in 7 .

23 Tanner JM, Whitehouse RH. Growth and development record. Boys: birth-19 years. Height and weight (a). Crane Mead Ware: Castlemad Publications, 1983.

24 Tanner JM, Whitehouse RH. Growth and development record. Boys: birth-19 years. Height and weight (b). Crane Mead Ware: Castlemad Publications, 1983.

25 Tanner TM. Growth at adolescence. Oxford: Blackwell Scientific, 1962:30-6.

26 American Alliance for Health, Physical Education, Recreation and Dance. The AAHPERD Physical Best Program. Reston, VA: AAHPERD, 1988

27 Ross JG, Gilbert GG. The national children and fitness study. A summary of findings. Fournal of the American Alliance of Physical Education, Recreation and Dance 1985;56: ance of

28 American College of Sports Medicine. Physical fitness testing. In: American College of Sports Medicine. ACSM's guidelines for exercise testing and prescription. 5th ed. guidelines for exercise testing and prescription.
Baltimore: Williams \& Wilkins. 1995:49-78.

29 American College of Sports Medicine. Exercise testing and ter 11. In: American College of Sports Medicine. ACSM's guidelines for exercise testing and prescription. 5th ed. Baltimore: Williams \& Wilkins. 1995:220-35.

30 Li RCT, Wu I, Maffulli N, Chan KM, Chan J. Eccentric and concentric isokinetic knee flexion and extension: a reliability study using the Cybex 6000 dynamometer. $\mathrm{Br} \mathcal{F}$ Sports Med 1996;30:156-60.

31 Norusis MJ. SPSS for Windows. Base System 6.0, 1994.

32 Rubin K, Schirduan V, Gendreau P, Sarfarazi M, Mendola R, Dalsky G. Predictors of axial and peripheral bone mineral density in healthy children and adolescents, with special
attention to the role of puberty. $\mathcal{F}$ Pediatr $1993 ; 123: 863-70$.

33 Theintz G, Buchs B, Rizzoli R, et al. Longitudinal monitoring of bone mass accumulation in healthy adolescents: evidence for a marked reduction after 16 years of age at the levels of lumbar spine and femoral neck in female subjects. f Clin Endocrinol Metab 1992;75:1060-65.

34 Blimkie CJR, Rice S, Webber CE, Martin J, Levy D, Gordon CL. Effects of resistance training on bone mineral content and density in adolescent females. Can f Physiol Pharmacol 1996;74:1025-33.

35 Sievanen H, Oja P, Vuori I. Precision of dual energy x-ray absorptiometry in determining bone mineral density and content of various skeletal sites. F Nucl Med 1992 33:113742 